Recepción: 20 / 01 / 2019

Aceptación: 19 / 03 / 2019

Publicación: 05 / 05 / 2019

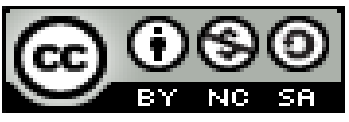

Ciencias de la salud

Artículo de Revisión

\title{
Complicaciones de cirugía maxilofacial en pacientes pediátricos
}

\section{Complications of maxillofacial surgery in pediatric patients}

\section{Complicações da cirurgia maxilofacial em pacientes pediátricos}

\author{
Abigail P. Saltos-Castro ${ }^{\mathrm{I}}$ \\ abi_saltos@hotmail.com \\ Paulina E. Durán-Mora ${ }^{\text {II }}$ \\ paupau_edm@hotmail.com \\ Hernán D. Toro-Barrera ${ }^{\text {III }}$ \\ hdavidtorob@gmail.com \\ Julio C. Cedeño-Quijije IV \\ jucecequi@hotmail.com \\ Hugo J. Saltos-Giler V \\ javilifer@hotmail.com \\ Olmedo X. Ruiz-Lara VI \\ olxarula@gmail.com
}

Correspondencia: abi_saltos@hotmail.com

\footnotetext{
I. Médico Cirujano; Médico general en funciones Hospitalarias; Hospital General IESS; Manta, Ecuador.

II. Médico; Médico Residente; Cirugía Plástica; Hospital General privado Durán; Ambato, Ecuador.

III. Médico Cirujano; Médico Residente de UCI Clínica Centeno; Médico Residente de Emergencia y Jefe de Guardia Hospital General IESS; Manta, Ecuador.

IV. Médico Cirujano; Médico Residente de Emergencia y Jefe de Guardia Hospital General IESS; Manta, Ecuador.

V. Médico Cirujano; Médico Residente de Área de Cirugía; Hospital General IESS; Manta, Ecuador.

VI. Médico; Médico Residente; Traumatología; Hospital General; Ibarra, Ecuador.
} 


\title{
Resumen
}

La Cirugía Maxilofacial, trata del diagnóstico y del tratamiento quirúrgico, coadyuvante de las enfermedades, traumatismos y defectos de los maxilares y regiones adyacentes. Los procedimientos realizados en este tipo de tratamientos en pacientes pediátricos deben seguir los mismos principios de las cirugías realizadas en pacientes adultos, respecto a todas las medidas que se deben tener en cuenta en bioseguridad, diagnostico, necesidad de tratamiento, instrumental y técnicas adecuadas; claro está, sin dejar de considerar en el niño el tamaño de su cavidad bucal, edad del paciente, preparación psicológica, consistencia del tejido óseo, presencia del germen dental permanente y control del dolor. Las complicaciones más comunes en este tipo de procedimiento quirúrgico son las infecciones que se dan en el territorio maxilofacial y se caracterizan por presentar cuadros frecuentes, de origen poli microbiano, con manifestaciones clínicas muy variables y que están asociadas a múltiples vías de ingreso de los microorganismos al territorio. Un gran porcentaje de estas infecciones se origina en la cavidad oral, principalmente en lesiones bacterianas que sufren los dientes. Estas anomalías se presentan de manera general, en los espacios potenciales y planos profundos de la región maxilofacial, cuya anatomía es compleja. La mayoría de ellas, responden apropiadamente al tratamiento quirúrgico y antimicrobiano, sin embargo, en algunos casos la diseminación local de la infección puede conducir al compromiso de espacios cervicales profundos, mediastinitis, trombosis del seno cavernoso o compromiso de la vía aérea. Su progresión y diseminación puede deberse a múltiples factores, incluyendo la inmuno - competencia del individuo, localización anatómica del proceso infeccioso, virulencia de los micro-organismos, patrones de resistencia de los organismos involucrados, así como también las decisiones del manejo terapéutico. De aquí, la importancia de analizar cuáles son las complicaciones que pudieran generarse en cirugías maxilofaciales de pacientes pediátricos y cómo será el manejo de éstas.

Palabras claves: Complicaciones de Cirugía Maxilofacial; Medidas de Bioseguridad; Infecciones Bacterianas; Tratamiento Antimicrobiano; Mediastinitis; Alveolitis.

\begin{abstract}
Maxillofacial Surgery, deals with the diagnosis and surgical treatment, coadjuvant of diseases, traumatisms and defects of the jaws and adjacent regions. The procedures performed in this type of treatment in pediatric patients should follow the same principles of surgeries performed in adult patients, with respect to all measures that should be taken into account in biosecurity, diagnosis,
\end{abstract}


Abigail P. Saltos-Castro; Paulina E. Durán-Mora; Hernán D. Toro-Barrera; Julio C. Cedeño-Quijije; Hugo J. SaltosGiler; Olmedo X. Ruiz-Lara

need for treatment, instruments and appropriate techniques; of course, without neglecting the size of the oral cavity in the child, patient's age, psychological preparation, consistency of bone tissue, presence of permanent dental germ and pain control. The most common complications in this type of surgical procedure are the infections that occur in the maxillofacial territory and are characterized by frequent pictures, of microbial poly origin, with very variable clinical manifestations and that are associated with multiple pathways for the entry of microorganisms. to the territory. A large percentage of these infections originate in the oral cavity, mainly in bacterial lesions suffered by the teeth. These anomalies are presented in a general way, in the potential spaces and deep planes of the maxillofacial region, whose anatomy is complex. Most of them respond appropriately to surgical and antimicrobial treatment, however, in some cases the local dissemination of the infection can lead to compromise of deep cervical spaces, mediastinitis, cavernous sinus thrombosis or compromise of the airway. Its progression and spread can be due to multiple factors, including the immunocompetence of the individual, anatomical localization of the infectious process, virulence of the micro-organisms, resistance patterns of the organisms involved, as well as the decisions of the therapeutic management. Hence, the importance of analyzing the complications that may arise in maxillofacial surgeries of pediatric patients and how they will be handled.

Keys words: Complications of Maxillofacial Surgery; Biosecurity measures; Bacterial infections; Antimicrobial Treatment; Mediastinitis; Alveolitis.

\section{Resumo.}

Cirurgia Maxilofacial, trata do diagnóstico e tratamento cirúrgico, coadjuvante de doenças, traumatismos e defeitos das mandíbulas e regiões adjacentes. Os procedimentos realizados nesse tipo de tratamento em pacientes pediátricos devem seguir os mesmos princípios das cirurgias realizadas em pacientes adultos, com relação a todas as medidas que devem ser consideradas na biossegurança, diagnóstico, necessidade de tratamento, instrumentos e técnicas apropriadas; é claro, sem negligenciar o tamanho da cavidade oral na criança, a idade do paciente, o preparo psicológico, a consistência do tecido ósseo, a presença de germe dentário permanente e o controle da dor. As complicações mais comuns neste tipo de cirurgia são as infecções que ocorrem em maxilo-facial e são caracterizadas por imagens frequentes, poli origem microbiana, com manifestações clínicas muito variáveis que estão associadas com várias vias de entrada de microrganismos para o território. Uma grande porcentagem dessas infecções se origina na cavidade bucal, principalmente em lesões 
bacterianas sofridas pelos dentes. Essas anomalias são apresentadas de maneira geral, nos espaços potenciais e planos profundos da região maxilofacial, cuja anatomia é complexa. A maioria deles responder adequadamente ao tratamento cirúrgico e antimicrobiano, no entanto, em alguns casos disseminação local da infecção pode levar a espaços cervicais profundos compromisso, mediastinite, trombose do seio cavernoso ou comprometimento das vias aéreas. Sua progressão e disseminação pode ser devido a vários fatores, incluindo imuno - competência do indivíduo, localização anatômica do processo infeccioso, virulência dos microrganismos, padrões de resistência das entidades envolvidas, bem como as decisões de gestão terapêuticas. Daí a importância de analisar as complicações que podem surgir nas cirurgias maxilofaciais de pacientes pediátricos e como elas serão tratadas.

Palavras chaves: Complicações da Cirurgia Maxilofacial; Medidas de biossegurança; Infecções bacterianas; Tratamento Antimicrobiano; Mediastinite; Alveolite.

\section{Introducción.}

Los traumatismos de los tejidos óseos y blandos de la cara, son una de las tres áreas fundamentales de la Cirugía Plástica, Reconstructiva y Maxilofacial, donde el abordaje de éstos, son entendidos en términos quirúrgicos como la complicación emergente de una fuerza física causante de lesiones al organismo, los cuales involucran todas las lesiones traumáticas que afectan al macizo facial (tercios superior, medio e inferior) donde se incluye el compromiso de los tejidos óseos y blandos faciales y las estructuras alveolo dentarias (hueso alveolar, piezas dentarias, tejidos gingivales y mucosa oral). (Caballero, 2014).

Lo antes expuesto lleva a considerar que, las complicaciones médicas posteriores a las cirugías maxilofaciales vienen dándose a nivel mundial, las mismas provienen de manera general de lesiones, infecciones tempranas postoperatorias, sangrados postoperatorios excesivos, fracturas, $\mathrm{o}$ daños a dientes adyacentes, y de igual forma, por lesiones en nervios cercanos. Los factores más comunes de este tipo de complicaciones, los constituyen la alveolitos alveolar o seca, la mala técnica quirúrgica (irrigación pobre durante la osteotomía), infecciones previas, que producen perdida del coagulo por la acción de las estreptoquinasa de las bacterias que disuelven el coagulo y los factores sistemáticos o enfermedades sistemáticas, las cuales son enfermedades como: la diabetes, discrasia 
sanguínea, uso de antiinflamatorios por procesos prolongados, excesos de anestésicos con vasoconstrictores y cambios hormonales en los periodos menstruales.

Estas complicaciones o lesiones, son clínicamente importantes pues tanto tejidos blandos como huesos de la cara confieren protección anterior al cráneo. El macizo facial constituye y se relaciona con estructuras y elementos anatómicos vitales, el manejo de sus lesiones o traumatismos amerita un diagnóstico oportuno y un manejo de urgencia adecuado. El objetivo principal de su tratamiento es conseguir la máxima recuperación funcional posible del segmento afectado mediante el establecimiento de condiciones que faciliten los procesos biológicos normales.

No obstante, existe la posibilidad de que posterior a la cirugía se presenten en el paciente varios grados de malestar, entre los que destacan el dolor extremo, inflamación exagerada y prolongada, dificultad respiratoria, dificultad para deglutir los alimentos y, finalmente, infección; sintomatologías éstas, que refieren la presencia de una complicación médica, la cual va a aparecer en el paciente (niño o niña), de manera diferente, según sea su situación clínica, el tiempo de cirugía realizada, la manipulación de los tejidos, el tipo de piel, uso de esteroides y la experiencia del cirujano.

Las complicaciones de cirugía maxilofacial, pueden ocurrir durante y/o después de la realización del acto quirúrgico. De acuerdo al tiempo de evolución, éstas serán inmediatas o mediatas o postoperatorias. Las inmediatas, afectan a piezas dentarias, tejidos blandos y tejidos duros, ocurriendo de manera intra - operatoria; las mediatas o postoperatorias, como alveolitis y hemorragias, por ejemplo, ocurren posteriormente a la extracción (Ramonny, 2016), La etiología de este tipo de patologías es variada, en muchos casos se debe a factores asociados a la técnica quirúrgica, estado de la pieza dentaria, o patología concurrente.

Es de destacar que, las complicaciones de cirugía maxilofacial varían en función del momento en que se producen, las mismas se clasifican en: complicaciones peri-operatorias, destacándose entre éstas: hemorragias, fracturas, desplazamientos de algún fragmento o de todo el TM, desgarros de tejidos blandos, enfisema subcutáneo, complicaciones neurológicas (lesión de estructuras nerviosas vecinas como el nervio lingual o el dentario inferior), luxación de la mandíbula, luxación del segundo molar, rotura de instrumental. 
Por otra parte, se encuentran las complicaciones postoperatorias, éstas se pronuncian de manera general luego de la cirugía, considerándose que el curso postoperatorio normal después de la exodoncia, es relativamente molesto y presenta un cierto grado de dolor, inflamación, sangrado y trismo. En este tipo de complicación, influye el tratamiento farmacológico, así como las instrucciones higiénico-dietéticas suministradas al paciente, tratan de evitar estos signos y síntomas. La aparición de cualquiera de ellos en intensidad superior a la normal debe ser considerada como complicación postoperatoria y ser tratada adecuadamente.

De la misma forma, pueden originarse complicaciones inmediatas: las cuales aparecen en las primeras horas o días tras la cirugía. Las principales son infección (alveolitis seca, celulitis, osteítis, abscesos), complicaciones de tejidos blandos (inflamación, trismo), lesiones vasculares (hemorragia, hematoma). En cambio, las complicaciones tardías: pueden aparecer a partir de los 15 días de la extracción: Infección (osteomielitis), formación de secuestros, dificultad de cicatrización periodontal, anomalías de la oclusión.

En razón de lo mencionado, se hace necesario conocer que las complicaciones y accidentes derivados de cirugías maxilofaciales dependen de muchos factores y pueden ocurrir, antes, durante y después de la realización del acto quirúrgico, dichas patologías tienen una incidencia a nivel mundial, para todos los casos, se reporta desde niveles que varían desde un $0.5 \%$ hasta un $68.4 \%$ encontrando en los niveles más altos de incidencia el caso de terceros molares inferiores, lo cual se atribuye a la densidad del hueso alveolar posterior de la mandíbula. Su incidencia en países como Cuba, Perú y Ecuador muestran que ocurren entre el 1 y el 6\% de todas las extracciones aparecen estas anomalías bucales (OMS, 2016).

El tratamiento recomendado por los especialistas para este tipo de complicaciones se basa de manera general en el manejo etiológico, incisión y drenaje de las colecciones purulentas y cuidados médicos complementarios como la hidratación, soporte nutricional, analgésicos, antipiréticos y antiinflamatorios. La antibioterapia se considera en casos en que las infecciones sean de rápida evolución, con evidencia de extensión y/o compromiso sistémico. (Ramonny 2016: 23). 


\section{Método.}

Para el desarrollo de este proceso investigativo, se plantea como metodología la encaminada hacia una orientación científica particular que se encuentra determinada por la necesidad de indagar en forma precisa y coherente una situación, en tal sentido, Dávila (2012), define la metodología "como aquellos pasos previos que son seleccionados por el investigador para lograr resultados favorables que le ayuden a plantear nuevas ideas". (p53.)

Lo citado por el autor, lleva a entender que el desarrollo de la acción investigativa busca simplemente coordinar acciones enmarcadas en una revisión bibliográfica con el fin de complementar ideas previas dirigidas a analizar las complicaciones de cirugía maxilofacial en pacientes pediátricos, para así, finalmente elaborar un cuerpo de consideraciones generales que ayuden a ampliar el interés propuesto.

\section{Tipo de Investigación}

Dentro de toda práctica investigativa, se precisan acciones de carácter metodológico mediante las cuales, se logra conocer y proyectar los eventos posibles que la determinan, así como las características que hacen del acto científico un proceso interactivo ajustado a una realidad posible de ser interpretada. En este sentido, se puede decir, que la presente investigación corresponde al tipo documental, definido por (Dávila, 2012), "se ocupa del estudio de problemas planteados a nivel teórico, la información requerida para abordarlos se encuentra básicamente en materiales impresos, audiovisuales y /o electrónicos”. (p.41).

En consideración a esta definición, la orientación metodológica permitió la oportunidad de cumplir con una serie de actividades inherentes a la revisión y lectura de diversos documentos donde se encontraron ideas explicitas relacionadas con los tópicos encargados de identificar a cada característica insertada en el estudio. Por lo tanto, se realizaron continuas interpretaciones con el claro propósito de revisar aquellas apreciaciones o investigaciones propuestas por diferentes investigadores relacionadas con el tema de interés, para luego dar la respectiva argumentación a los planteamientos, en función a las necesidades encontradas en la indagación. 


\section{Fuentes Documentales}

El análisis correspondiente a las características que predomina en el tema seleccionado, llevan a incluir diferentes fuentes documentales encargadas de darle el respectivo apoyo y en ese sentido cumplir con la valoración de los hechos a fin de generar nuevos criterios que sirven de referencia a otros procesos investigativos. Para (Arias, 2010), las fuentes documentales incorporadas en la investigación documental o bibliográfica, "representa la suma de materiales sistemáticos que son revisados en forma rigurosa y profunda para llegar a un análisis del fenómeno”. (p.41). Por lo tanto, se procedió a cumplir con la realización de una lectura previa determinada por encontrar aquellos aspectos estrechamente vinculados con el tema, para luego explicar mediante un desarrollo las respectivas apreciaciones generales de importancia.

\section{Técnicas para la Recolección de la Información}

La conducción de la investigación para ser realizada en función a las particularidades que determinan a los estudios documentales, tiene como fin el desarrollo de un conjunto de acciones encargadas de llevar a la selección de técnicas estrechamente vinculadas con las características del estudio. En tal sentido, (Arias Ob cit) refiere, que es "una técnica particular para aportar ayuda a los procedimientos de selección de las ideas primarias y secundarias". (p. 71).

Por ello, se procedió a la utilización del subrayado, resúmenes, fichaje, como parte básica para la revisión y selección de los documentos que presentan el contenido teórico. Es decir, que mediante su aplicación de estas técnicas se pudo llegar a recoger informaciones en cuanto a la revisión bibliográfica de los diversos elementos encargados de orientar el proceso de investigación. Tal como lo expresa, (Arias Ob cit) "las técnicas documentales proporcionan las herramientas esenciales y determinantes para responder a los objetivos formulados y llegar a resultados efectivos" (p. 58). Es decir, para responder con eficiencia a las necesidades investigativas, se introdujeron como técnica de recolección el método inductivo, que hizo posible llevar a cabo una valoración de los hechos de forma particular para llegar a la explicación desde una visión general.

Asimismo, se emplearon las técnicas de análisis de información para la realización de la investigación que fue ejecutada bajo la dinámica de aplicar diversos elementos encargados de determinar el camino a recorrer por el estudio, según, (Arias, Ob cit) las técnicas de procesamiento 
de datos en los estudios documentales "son las encargadas de ofrecer al investigador la visión o pasos que debe cumplir durante su ejercicio, cada una de ellas debe estar en correspondencia con el nivel a emplear" (p. 123). Esto indica, que para llevar a cabo el procesamiento de los datos obtenidos, es necesario establecer las técnicas que serán seleccionadas, destacándose en este caso, de manera particular: fichas de resumen, textual, registros descriptivos entre otros, los mismos se deben ajustar al nivel que ha sido seleccionado

\section{Resultados.}

\section{Complicaciones de Cirugía Maxilofacial}

En todos los campos de la Cirugía Bucal es primordial el diagnóstico correcto, al cual se da a través del examen clínico al paciente y la realización de distintas pruebas complementarias. Con todo ello, el profesional en base a sus conocimientos y experiencia, establecerá un diagnóstico certero; posteriormente podrá emplear distintos métodos de tratamiento. En el caso de la cirugía maxilofacial se debe proporcionar atención antes de la intervención quirúrgica, inmediatamente después de ella, y a largo plazo, a fin de curar la enfermedad que afecta al paciente.

\section{Imagen $N^{\circ}$ 1. Complicación Post Operatoria}

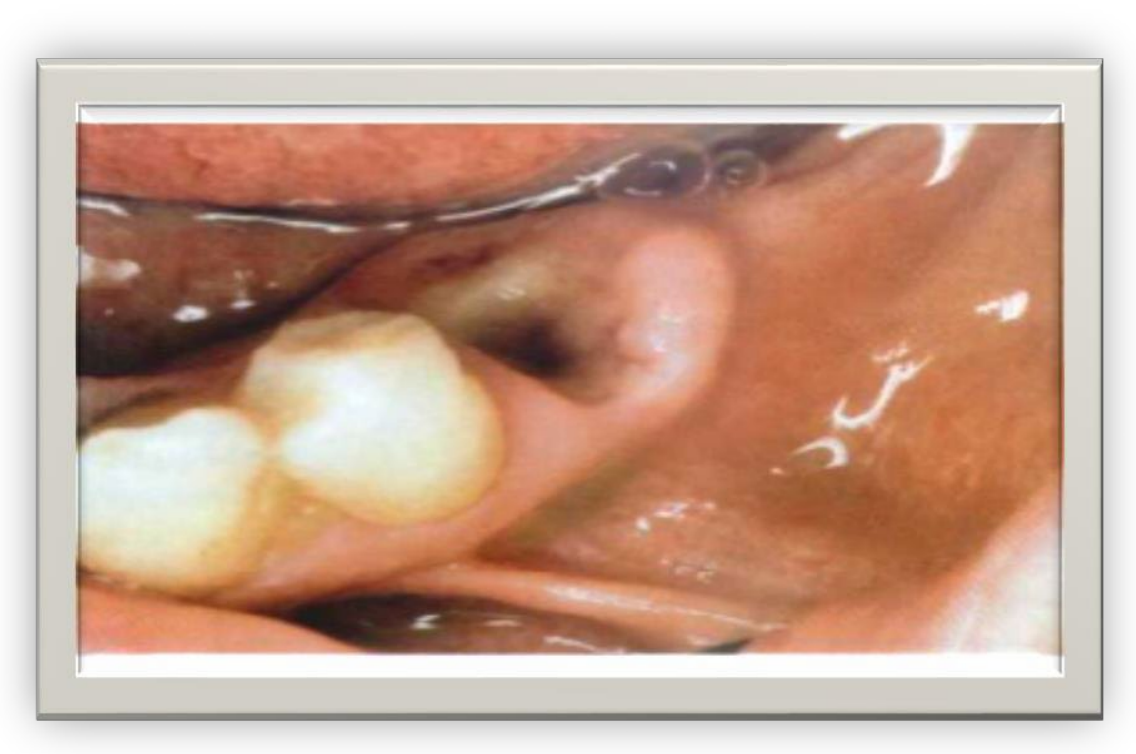

Fuente: Vera (2015) 
Para evitar el riesgo a complicaciones, es necesario que el profesional de odontología estudie y repase continuamente la anatomía quirúrgica de las zonas donde efectúa su actividad quirúrgica. Todo procedimiento de cirugía bucal amerita el desarrollo de un diagnóstico correcto, el cual deberá ser llevado a cabo mediante el desarrollo de un buen examen clínico y con la ayuda de exámenes complementarios para posteriormente emplear distintos métodos de tratamiento.

Los procedimientos quirúrgicos pueden ser simples o complejos, pero cualquiera fuera el caso se debe contar con una adecuada iluminación del campo operatorio, acceso suficiente a la zona operatoria y un campo operatorio libre de exceso de fluidos. La curación de la herida quirúrgica vendrá influenciada por diversos factores, destacándose entre ellos:

- Estado general del paciente.

- Existencia de enfermedades hepáticas y renales graves.

- Estado nutricional del paciente alterado.

- El paciente diabético no controlado responde mal a un procedimiento quirúrgico y suele presentar infecciones secundaria en el postoperatorio.

- Presencia de cuerpos extraños.

- Existencia previa de infección en el campo quirúrgico.

Las compilaciones más comunes que se pueden presentar durante y después de la cirugía dependen del sitio donde se ubique el diente, las más comunes en el arco inferior son daño al nervio dentario y lingual. Estas complicaciones de manera general son entendidas como accidentes o fenómenos adversos que sobrevienen durante un acto operatorio o después de él. Dentro de las complicaciones más comunes encontramos:

1.- Alveolitis: Representa la infección pútrica del alveolo dentario después de una extracción. Es la complicación más frecuente, se observa entre el 1\% y el 4\% de las extracciones dentales normales, elevando su frecuencia entre el $20 \%$ y el 30\% de los casos de exodoncia de terceras molares retenidas. Dentro de la etiología, no existe actualmente un conocimiento concreto de cuál es la etiología del proceso, se considera como una afección multifactorial. Una de las complicaciones más frecuentes que se presentan después de realizar una extracción dental es la osteítis alveolar aguda o alveolitis. Se trata de una entidad que se presenta con dolor intenso, continuo y que inicialmente 
puede encontrarse localizado pero puede irradiarse en gran parte de la región facial. Para (Cuevas, 2014):

La Osteítis alveolar representa un proceso localizado y focal en el hueso, que está en relación con infecciones de origen dentario, como los abscesos dentarios, las infecciones de los gérmenes dentarios y sobre todo por las terceras molares que se infectan localmente. (p.16)

Entre los factores más comunes que deben ser considerados como posibles causas de la alveolitos alveolar o seca, se encuentra: la mala técnica quirúrgica (irrigación pobre durante la osteotomía), infecciones previas, que producen perdida del coagulo por la acción de las estreptoquinasa de las bacterias que disuelven el coagulo. Así mismo, se encuentran los factores sistemáticos o enfermedades sistemáticas, las cuales son enfermedades como: la diabetes, discrasia sanguínea, uso de antiinflamatorios por procesos prolongados, excesos de anestésicos con vasoconstrictores y cambios hormonales en los periodos menstruales. (Cuevas 2014: 12)

Dentro de la sintomatología de esta enfermedad se observa enrojecimiento de la zona, dolor, tumefacción, y aumento de la temperatura local, esta afección casi nunca se XXIV acompaña de procesos febriles. El estudio radiográfico muestra una imagen radio lúcida, debido al proceso osteolítico del hueso. La osteítis en su forma aguda presenta fenómenos supurativos, produce un estado de tumefacción acompañado de dolor, ligera elevación térmica. (Pierro, 2014).

En efecto, la alveolitis representa una complicación que deviene de un estado necrótico del proceso alveolar o septos óseos que ante la ausencia de vasos sanguíneos impide la formación del coágulo y éste se desintegra de manera parcial o total. Se describen dos tipos: alveolitis húmeda y alveolitis seca (Palacios, 2015). Esta enfermedad se caracteriza por la aparición de dolor postoperatorio dentro del ler al 3er día de realizada la cirugía que no cede frente a analgésicos, malestar general, pérdida o disgregación del coágulo sanguíneo y en algunos casos acompañada de halitosis.

Cuando se hace la diferenciación entre el tipo húmeda y seca, la primera contaría con la presencia de tejido granulomatoso, dolor moderado, espontáneo y provocado, por otra parte, el subtipo seca, se caracterizaría por cursar con un alveolo abierto y paredes óseas sin recubrimiento, un dolor intenso de tipo constante e irradiado y el cual se exacerba durante la masticación generando impotencia 
funcional (Palacios 2015: 15). Su diagnóstico, es predominantemente clínico y su tratamiento es local, removiendo el tejido afectado para promover la formación de un coágulo de novo, con el objetivo de disminuir el dolor y favorecer la cicatrización del alveolo.

\section{Imagen $N^{\circ}$ 2. Complicación por extracción muy fuerte}

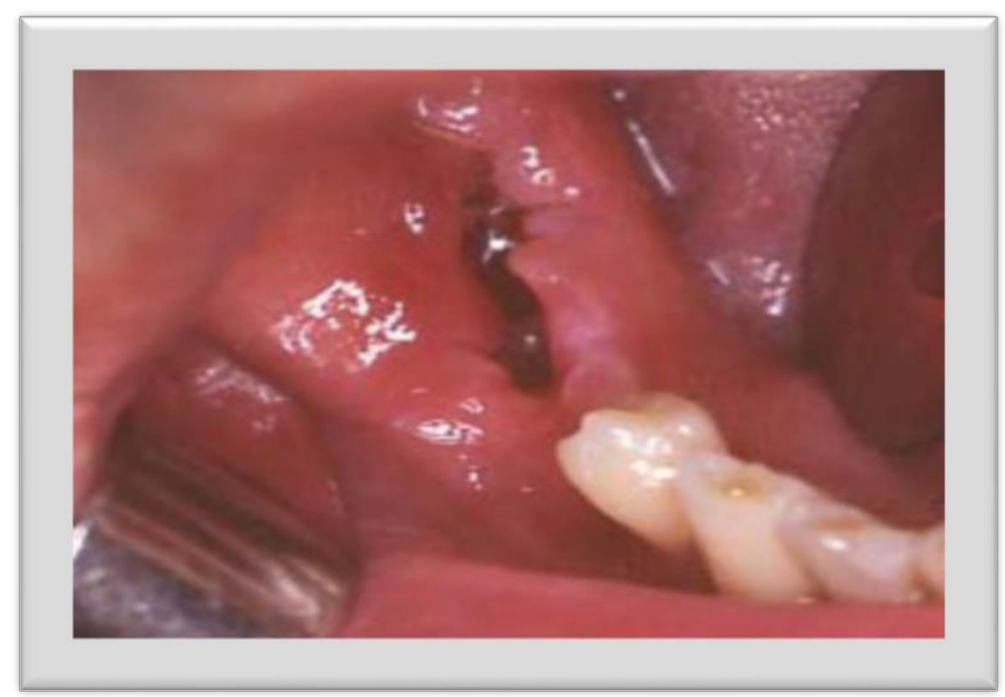

Fuente: Vera (2015)

La etiología de la Alveolitis es multifactorial, debido a que es un estado en el cual hay pérdida total o parcial del coágulo sanguíneo, superficies óseas sensibles, cubiertas por una superficie gris amarillenta de tejido necrótico y con olor fétido. Al principio el coágulo adquiere un color gris sucio y después se desintegra hasta quedar una cavidad ósea amarilla grisácea. Al verla, por primera vez, se puede observar que la cavidad no está vacía del todo, sino que contiene un coágulo sanguíneo necrosado en parte.

No obstante, aunque no suele haber supuración, usualmente existe fetidez y un intenso dolor irradiado. Este dolor suele describirse como intenso profuso y pulsátil. Este dolor se debe a la irritación química y térmica de las terminaciones nerviosas expuestas en el ligamento periodontal y en el hueso alveolar. Los síntomas suelen comenzar entre el segundo y el quinto día luego de la extracción dental.

2.- Hemorragia: Las complicaciones hemorrágicas son quizás las más llamativas, una pequeña hemorragia es normal tras la cirugía, sin embargo puede ser abundante y difícil de cohibir. La 
hemorragia alveolar es otra de las complicaciones post operatorias más frecuentes; después de la realización de la extracción es normal que el paciente sangre de 30 a 60 minutos pasado este tiempo el sangrado persiste hay que encontrar las causa que lo originan las cuales pueden ser locales o generales. (Sava, 2014).

- Locales como: desgarro o cortes accidentales, tejidos muy inflamados, no seguir las indicaciones post-exodoncia, hiperemia de tejidos bandos, lesión de vasos sanguíneos, uso indebido del aspirador quirúrgico

- Generales como: alteraciones plaquetarias, enfermedades hepáticas, coagulopatías, trastornos vasculares, consumo de fármacos y pacientes fumadores.

La hemorragia post extracción presenta baja prevalencia, cercana al $0,5 \%$ y puede variar. Corresponde al sangrado del alvéolo después de efectuada la cirugía y que persiste a pesar de las medidas hemostáticas realizadas en primera instancia por el odontólogo y por el paciente, determinando una consulta de urgencia. (Venzit, 2015). De allí, que un evento de sangrado se puede considerar clínicamente significativo si se mantiene posterior a 12 horas, obligando al paciente a asistir a un servicio de urgencias, resulta en el desarrollo de un hematoma o equimosis considerables en los tejidos blandos orales o cuando requiera de una transfusión sanguínea.

Sus causas pueden ser el no seguir las indicaciones post exodoncia dadas por el profesional al paciente, como también por antecedentes no pesquisados en la anamnesis o el examen físico (discrasias sanguíneas o tratamiento anticoagulante, por ejemplo). El tratamiento inoportuno o inadecuado puede significar un compromiso del estado general del paciente que puede ir desde una lipotimia, pasando por una anemia hasta un shock hipovolémico.

En general, para pacientes sin antecedentes sistémicos el tratamiento será a través de medidas locales, mediante el uso de gelatina reabsorbible, sutura de ser necesario y compresión local. En el caso de pacientes con patologías sanguíneas se debe realizar la oportuna derivación a hospital o centro de atención terciaria.

3.- Queilitis Angular: El termino queilitis es el más común para designar estados inflamatorios de la submucosa labial o comisuras labiales. Esta lesión de los labios algunos autores la clasifican dentro 
de las formas de presentación de la candidiasis. La candidiasis es la micosis más frecuente de la boca que aparece en la infancia, aunque puede atacar a adultos, provocando placas blancas adherentes distribuidas irregularmente en la mucosa bucal, que suele acompañarse de inflamación y grietas de las comisuras labiales y de costras en labios. (Venzit 2015: 22).

Generalmente la queilitis se encuentra para su estudio dentro de la clasificación de la candidiasis, si tenemos en cuenta que la queilitis es el estado inflamatorio de la mucosa al nivel del ángulo labial, clasificándose de la siguiente forma:

- Queilitis mucosa aguda y crónica.

- Queilitis microbiana impetigenosa y estreptocócica: aguda y crónica.

- Queilitis de contacto; puede ser labial, queilitis o dermatitis por pasta dentrífica, o queilitis alimentaria.

- Queilitis comisural (perleche). Además menciona las llamadas queilitis glandulares y las macroqueilitis.

Agrupando los diferentes criterios, para facilitar su estudio, las queilitis pueden ser producidas por:

- Factores generales: Trastornos nutricionales. Alteraciones endocrinas (diabetes). Anemias. Carencias vitamínicas. Defectos de inmunidad. Tratamientos citotóxicos o inmunosupresores. Etílicos cirróticos. Vejez.

- Factores locales: Disminución de la dimensión vertical oclusiva en pacientes dentados y en desdentados total o parcial, rehabilitada o no. Irritantes (sustancias químicas). Tratamientos odontológicos traumáticos Hipersensibilidad. Hábitos o traumatismos provocados por el mordisqueo de las comisuras provocando irritación crónica.

4.- Otras complicaciones infecciosas: La infección del sitio quirúrgico es una complicación severa que ocurre después de la cirugía y su definición es principalmente clínica: secreción purulenta alrededor de la herida o celulitis difusa de la herida (OMS, 2015) o, el enrojecimiento y dolor en relación a la herida, drenaje purulento y fiebre. La infección suele contraerse durante la propia operación, ya sea en forma exógena (es decir, del aire, del equipo médico, los cirujanos y otro 
personal médico), endógena (de la flora de la piel o del sitio de la operación) o, en raras ocasiones, de la sangre empleada en la intervención quirúrgica.

Este tipo de complicaciones, representan un problema grave que limita los beneficios potenciales de las intervenciones quirúrgicas (OMS, 2015). El principal factor de riesgo es el grado de contaminación durante el procedimiento (limpio-contaminado en el caso de cirugía maxilofacial, por su acceso a la cavidad bucal y ausencia de infección previa) que en gran medida depende de la duración de la operación y del estado general del paciente como la edad, diabetes mellitus, tabaquismo, respuesta inmune alterada y malnutrición.

Otros factores comprenden la calidad de la técnica quirúrgica, presencia de cuerpos extraños, virulencia de los microorganismos, infección concomitante en otros sitios y la experiencia del equipo quirúrgico (Sierra, 2015). De acuerdo con la literatura médica, el riesgo de la infección del sitio quirúrgico es proporcional a la duración de la cirugía, es decir, a mayor tiempo operatorio, mayor es la posibilidad de la ocurrencia de una infección debido al aumento en la exposición de los tejidos. El tiempo operatorio se mide en minutos y se define como el tiempo que transcurre desde la primera incisión hasta el cierre completo de la herida, y también puede reflejar la complejidad del procedimiento y de la técnica quirúrgica (Basco, 2015).

Estas complicaciones suelen estar precedidas en algunos de los casos de la intervención de diferentes factores de riesgo, entre los cuales se pueden mencionar: caries profundas, dientes con endodoncia, enfermedades periodontales, fistulas y extracciones traumáticas; de allí, que este tipo de elementos han dado vida a numerosos estudios, los cuales centran su propósito en determinar cuál de ellos es el más frecuente en este tipo de afecciones bucales. Como ejemplo de ello, se presenta el estudio de (Zayas, 2016), de nombre: Factores que inciden en las complicaciones médicas de cirugía maxilofacial, encontrándose entre sus resultados lo siguiente: 
Cuadro $N^{\circ} 1$. Factores de riesgo que inciden en complicaciones de cirugía maxilofacial en pacientes pediátricos

\begin{tabular}{|c|c|c|c|c|c|c|}
\hline \multirow[t]{3}{*}{ Factores de riesgo. } & \multicolumn{6}{|c|}{$\begin{array}{c}\text { Complicaciones de la extracción dental } \\
\text { en relación a: }\end{array}$} \\
\hline & \multicolumn{2}{|c|}{$\begin{array}{l}\text { Pieza } \\
\text { dentaria }\end{array}$} & \multicolumn{2}{|c|}{ Tej.duros. } & \multicolumn{2}{|c|}{$\begin{array}{l}\text { Tej. } \\
\text { blandos. }\end{array}$} \\
\hline & No & $\%^{*}$ & No & $\%^{*}$ & No & $\%{ }^{*}$ \\
\hline Caries profundas $\circ$ grandes obturaciones. & 74 & 90,2 & 25 & 75,7 & 18 & 64,2 \\
\hline Dientes desvitalizadas o con endodoncia & 67 & 81,7 & 23 & 69,6 & 13 & 46,4 \\
\hline Enfermedad periodontal. & 8 & 9,7 & 21 & 63,6 & 10 & 35,7 \\
\hline Presencia de fístulas. & 45 & 57,3 & 16 & 48,4 & 8 & 28,5 \\
\hline Extracciones traumáticas & 31 & 37,8 & 14 & 42,4 & 13 & 46,4 \\
\hline
\end{tabular}

Fuente: Zayas (2016)

Al analizar los factores de riesgo presentes en los pacientes pediátricos con complicaciones inmediatas de la cirugía maxilofacial se comprobó que el 90,2\% de los pacientes que sufrieron complicaciones de la extracción dental con relación a la pieza dentaria presentaban piezas dentarias con caries profundas o grandes obturaciones; el 57,3\% presentaba fístulas a nivel del diente a extraer y raíces curvas, signo de que padecía de alguna patología pulpar crónica, en el 37,8\% de los casos la cirugía fue trabajosa y prolongada y el 81,7 \% tenía piezas dentarias desvitalizadas o con endodoncia.

Finalmente, se pudo observar que en complicaciones inmediatas con relación a los tejidos duros igualmente el factor de riesgo que en mayor cuantía se observó fue en el gran número de pacientes pediátricos que presentaban piezas dentarias con caries profundas o grandes obturaciones 75,7\% de los pacientes objeto de este tipo de complicación. Otro factor de riesgo que se observó en un gran número de pacientes fueron las piezas dentarias desvitalizadas o con endodoncia 69,6\% y la enfermedad periodontal que fue diagnosticada al 63,6\% de los casos. El 48,4\% presentó fístulas a nivel del diente a extraer y el 42,4\% fue objeto de una extracción traumática. 


\section{Conclusiones.}

La cirugía maxilofacial pediátrica engloba la cirugía de toda la estructura facial, tejidos blandos y duros, de los niños y adolescentes. El equipo de cirujanos del Instituto Maxilofacial está especializado en cirugía maxilofacial infantil, juvenil y adolescente, y puede tratar tanto malformaciones congénitas como problemas adquiridos.

Las complicaciones de cirugía maxilofacial, pueden presentarse en cualquier procedimiento quirúrgico y pueden ocurrirle hasta al cirujano más experimentado. De allí, la importancia de realizar un diagnóstico específico, el cual le permita al profesional de la odontología considerar las posibles complicaciones que este tipo de procedimiento quirúrgico pudiera generarse en su paciente y de esa forma poseer la habilidad y el conocimiento necesario para modificar el procedimiento ante cualquier eventualidad médica que se presentara.

Las compilaciones de cirugía maxilofacial más comunes que se pueden presentar durante y después de la cirugía dependen del sitio donde se ubique el diente, las más comunes en el arco inferior son daño al nervio dentario y lingual. Estas complicaciones de manera general son entendidas como accidentes o fenómenos adversos que sobrevienen durante un acto operatorio o después de él.

Entre las complicaciones más comunes de la cirugía maxilofacial se encuentra la alveolitis, la cual representa una complicación que deviene de un estado necrótico del proceso alveolar o septos óseos que ante la ausencia de vasos sanguíneos impide la formación del coágulo y éste se desintegra de manera parcial o total. Se describen dos tipos: alveolitis húmeda y alveolitis seca. Se caracteriza por la aparición de dolor postoperatorio dentro del 1er al 3er día de realizada la cirugía que no cede frente a analgésicos, malestar general, pérdida o disgregación del coágulo sanguíneo y en algunos casos acompañada de halitosis.

Otra de las complicaciones de este tipo de cirugía en pacientes pediátricos, se encuentra representada por la hemorragia, la cual corresponde al sangrado del alvéolo después de efectuada la cirugía y que persiste a pesar de las medidas hemostáticas realizadas en primera instancia por el odontólogo y por el paciente, determinando una consulta de urgencia. Sus causas pueden ser el no seguir las indicaciones post exodoncia dadas por el profesional al paciente, como también por 
antecedentes no pesquisados en la anamnesis o el examen físico (discrasias sanguíneas o tratamiento anticoagulante, por ejemplo).

En el mismo orden, se señala la queilitis reconocida como una de las complicaciones más comunes pues se caracteriza por estados inflamatorios de la submucosa labial o comisuras labiales. Esta lesión de los labios algunos autores la clasifican dentro de las formas de presentación de la candidiasis. La candidiasis es la micosis más frecuente de la boca que aparece en la infancia, aunque puede atacar a adultos, provocando placas blancas adherentes distribuidas irregularmente en la mucosa bucal, que suele acompañarse de inflamación y grietas de las comisuras labiales y de costras en labios.

Del mismo modo, se describen las complicaciones que provienen del sitio quirúrgico, las cuales ocurren después de la cirugía y su definición es principalmente clínica: secreción purulenta alrededor de la herida o celulitis difusa de la herida, o, el enrojecimiento y dolor en relación a la herida, drenaje purulento y fiebre. La infección suele contraerse durante la propia operación, ya sea en forma exógena (es decir, del aire, del equipo médico, los cirujanos y otro personal médico), endógena (de la flora de la piel o del sitio de la operación) o, en raras ocasiones, de la sangre empleada en la intervención quirúrgica.

\section{Bibliografia.}

Arias, F. (2010). Paradigmas de la Investigación Científica. España: Editorial: Luces.

Basco, L. (2015). Complicaciones de la Cirugía Maxilofacial. 2da edición, Médica Panamericana, 32.

Caballero, P. (2014). Complicaciones de la Cirugía Maxilofacial. Revista Actualizada de Salud de la Escuela de Santiago de Chile, 13.

Cuevas, J. (2014). Factores que originan la Alveolitis Seca. Revista Vida y Salud de la Universidad Central de Venezuela UCV, Caracas, 23.

Dávila, N. (2012). Paradigmas de la Investigación Científica. Pereire, Colombia: Editorial: Las Brisas.

OMS, O. M. (2016). Complicaciones en pacientes pediátricos de la cirugía Maxilofacial. $2 d a$ edición, Revista Médica Panamericana de Odontología., 21.

Palacios, E. (2015). Causas y Consecuencias de la Alveolitis Seca. España: Editorial: Mediterráneo. 
Abigail P. Saltos-Castro; Paulina E. Durán-Mora; Hernán D. Toro-Barrera; Julio C. Cedeño-Quijije; Hugo J. SaltosGiler; Olmedo X. Ruiz-Lara

Pierro, E. (2014). Complicaciones de Cirugía Maxilofacial. España: Las Nubes.

Ramonny, C. (2016). Complicaciones Maxilofaciales en pacientes Pediátricos. Revista Salud Bucal de la Escuela de Odontología de la Universidad de la Habana Cuba, 19.

Sava, C. (2014). Complicaciones Hemorrágicas de la Cirugía Maxilofacial. Revista de Salud Pública en México, 19.

Sierra, Y. (2015). Factores que inciden en complicaciones de Cirugía Maxilofacial. Revista de Atención Asistencial y Sanitaria , 34.

Venzit, M. (2015). Hemorragias por complicaciones Maxilofaciales. Revista de Salud Pública en México, 23.

Zayas, G. (2016). Factores de riesgo de cirugías Bucales. Revista Odontológica de la Universidad Nacional de Perú, 27. 